\title{
Unsymmetrical load effect of geologically inclined bedding strata on tunnels of passenger dedicated lines
}

\author{
Benguo HE*, Zhiqiang ZHANG, Yu CHEN \\ School of Civil Engineering, Southwest Jiaotong University, Chengdu 610031, China
}

\begin{abstract}
In order to study the unsymmetrical load effect in geological bedding strata for the Muzhailing tunnel on the Lanzhou-Chongqing passenger dedicated line in China, we investigated the deformation, mechanical response and pressure of the surrounding rock and the mechanical characteristics of bolts of the tunnel. The results suggest that open zones appear at arch and invert where joints open up, when layered stratum is horizontal, or when the dip angle of inclined bedding is small. Open zones occur perpendicular to a joint. The failure mode is bending disjunction at the arch. What's more, with the dip angle increasing, tunnel excavating would induce shear zones where joints experience a certain shear displacement, and lead to obvious geological bedding unsymmetrical load. The failure mode is shear damage. For the joint dip angle in the range of $75-90^{\circ}$, the failure mode is flexural crushing at the wall and vertical shear rupture above the arch. The restraining effect of two sides weakens for vertical dip. On the whole, shear failure instability trend would occur and the tunnel collapses evenly. When the angle between the bolt and structure plane is greater than $23^{\circ}$, bolts can enhance the shearing stiffness of joint plane. Unfortunately, in the general purpose graph of tunnel for $250 \mathrm{~km} / \mathrm{h}$ of passenger dedicated lines, the bolts have equal length and spacing. The rationale behind this is worthy of further study. For inclined bedding, the surrounding rock pressure at the left wall is more than that at the right wall. In addition, lining is likely to be damaged at left shoulder and side wall. With the dip angle increasing, the unsymmetrical load gradually achieves symmetry. Asymmetry design for support is recommended to reduce the unsymmetrical load on lining disturbed by excavation.
\end{abstract}

Key words: geological bedding strata; unsymmetrical load tunnel; bolt support; surrounding rock pressure; stability

(C) 2012 JMT. All rights reserved.

\section{Introduction}

$\mathrm{S}$ tructural planes weaken rock mechanical properties considerably. Furthermore, tunnel excavating would lead to sliding of joint planes and obvious unsymmetrical load effects of geological bedding strata. Unfortunately, the instability mode of a tunnel is quite different from the traditional loosing medium theory. With the continuous development of tunnels and underground engineering in China's railway and road transport, a considerable amount of research has been done for complex geological conditions during the last decade [1].

In connection with tunnels of jointed rock mass, Shen and Barton [2] investigated three zones around a tunnel disturbed by excavation in an ideally jointed rock mass: failure zone, open zone, and shear zone. The change of the three zones depends on different joint spacings and orientations. Idris et al. [3] simulated the evolution of

\footnotetext{
Received Oct. 15, 2011; revision accepted Dec. 28, 2011

${ }^{*}$ Corresponding author. Tel.: +86-15928989062

E-mail: benguohe@126.com (B.G. HE)

(C) 2012 JMT. All rights reserved

doi: 10.3969/j.issn.2095-087X.2012.01.004
}

masonry joints mechanical behavior in built tunnels and quantified the influence of the mechanical proprieties on the tunnel behavior by the experimental design method and distinct elements numerical modelling. Ma and Ji [4] studied the effect of joint orientation on fragmentation modes and penetration rate under TBM (tunnel boring machine) disc cutters based on tests. In their work, two kinds of concrete with different strengths were adopted to simulate rock samples. Wang [5] adopted the discrete element method (DEM) to research the interaction among the jointed rock mass, large section structure of the tunnel, and the mechanical state of the whole tunnel system in the sequential process of the excavation and construction. Liu et al. [6] analyzed the effect of joint density on the deformation and failure of surrounding rocks by physical modeling method.

However, these aforementioned studies neglected unsymmetrical load effects of geologically inclined bedding strata on the tunnel. Generally, the unsymmetrical loading on the tunnel lining can be attributed to terrain, construction, and geological structure factors. In the above factors, calculation methods of the unsymmetrical load for terrain and construction reasons have been established maturely. In contrast, the calculation method 
for geologically inclined bedding strata was rarely reported. In the present work, the unsymmetrical load effect on tunnel stability, mechanics of bolts, and surrounding rock pressure were investigated for geological bedding strata with different dip angles. The work carried out has the potential to provide guidance for robust tunnel construction and design.

\section{Engineering situation}

Muzhailing tunnel is a key project on LanzhouChongqing passenger dedicated line, located in Gansu province in the Northwest China. The length of the tunnel is $19.0 \mathrm{~km}$. Due to the complex multi-stage structural superimposition, various shapes of folding structures are formed, including complicated faults. The rock mass has fracture characteristics, such as tectonic evolution, and large scale distribution of slates and carbonaceous slates. The total length of the carbonaceous slates is $8850 \mathrm{~m}$, accounting for $46.53 \%$ of the total length of the tunnel. Mechanical properties of carbonaceous slate depend on the dip angle of the structural plane. The rock mass has a high joint connectivity. Joint spacing is $0.2-0.5 \mathrm{~m}$. As a result of bedding plane slip failure, spalling occurred at the left wall of the concrete lining (Fig. 1).

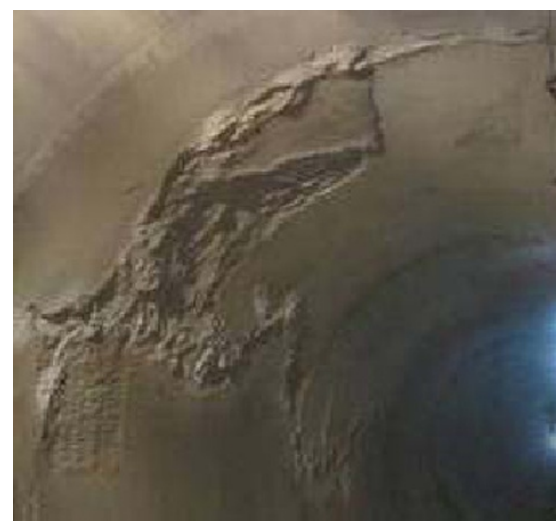

Fig. 1 Spalling of lining under geological bedding unsymmetrical load

\section{UDEC model and calculation parameters}

UDEC (Universal Distinct Element Code) software is suitable to simulate the separation process of a joint system. Moreover, it can identify the emergence of a new joint for a joint plane automatically, and reflect the mechanical behavior of a structural plane accurately [7-8].

\subsection{Discrete element model and boundary constraints}

According to the general purpose graph of tunnel for $250 \mathrm{~km} / \mathrm{h}$ of passenger dedicated lines in China [9-10], the stability of surrounding rock is examined under different dip angles, such as $0^{\circ}, 15^{\circ}, 30^{\circ}, 45^{\circ}, 60^{\circ}, 75^{\circ}$, and $90^{\circ}$. The mesh boundary is about $110 \mathrm{~m}$ in the horizontal direction, and about $120 \mathrm{~m}$ in the vertical direction. A computational model as shown in Fig. 2 is built to study the geological bedding unsymmetrical load by using the 2D DEM code UDEC [11]. Moreover, the tunnel has a maximum buried depth of $100 \mathrm{~m}$ from the arch, and the distance from the upper boundary to the arch of the tunnel is $60 \mathrm{~m}$. Therefore, the gravity pressure from the above rock mass is applied on the upper boundary. Normal constraints are applied on the left, right, front, back, and lower boundaries of the model, which means the displacement is zero.

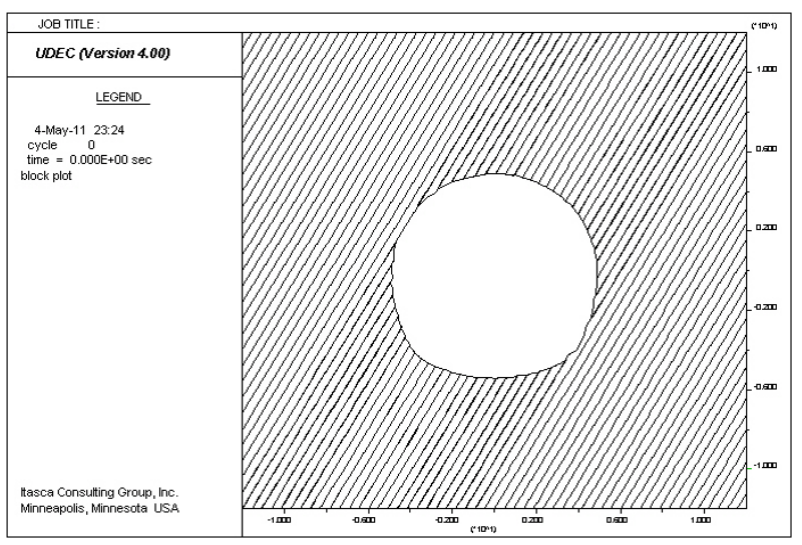

Fig. 2 Computation model

\subsection{Calculation parameters}

The elasto-perfectly plastic model of Mohr-Coulomb yield criterion was used for rock blocks, and the contactCoulomb slip model was adopted for the structural plane. The aforementioned models were selected based on the site geological survey report of Muzhailing tunnel, similar construction experience, and the related literature [12-15]. The properties of rock blocks and joint planes are listed in Table 1 and Table 2, respectively.

Table 1 Mechanical properties of rock blocks

\begin{tabular}{ccccc}
\hline $\begin{array}{c}\text { Density } \\
\left(\mathrm{kN} \cdot \mathrm{m}^{-3}\right)\end{array}$ & $\begin{array}{c}\text { Elastic } \\
\text { modulus }(\mathrm{GPa})\end{array}$ & $\begin{array}{c}\text { Poisson's } \\
\text { ratio }\end{array}$ & $\begin{array}{c}\text { Cohesion } \\
(\mathrm{MPa})\end{array}$ & $\begin{array}{c}\text { Friction } \\
\text { angle }\left(^{\circ}\right)\end{array}$ \\
\hline 23 & 5 & 0.32 & 2.80 & 35 \\
\hline
\end{tabular}

Table 2 Mechanical properties of joint planes

\begin{tabular}{ccccc}
\hline $\begin{array}{c}\text { Normal } \\
\text { stiffness } \\
\left(\mathrm{Gpa} \cdot \mathrm{m}^{-1}\right)\end{array}$ & $\begin{array}{c}\text { Shearing } \\
\text { stiffness } \\
\left(\mathrm{Gpa} \cdot \mathrm{m}^{-1}\right)\end{array}$ & $\begin{array}{c}\text { Friction } \\
\text { angle }\left(^{\circ}\right)\end{array}$ & $\begin{array}{c}\text { Cohesion } \\
(\mathrm{MPa})\end{array}$ & $\begin{array}{c}\text { Tensile } \\
\text { strength } \\
(\mathrm{MPa})\end{array}$ \\
\hline 6.3 & 2.3 & 10 & 0.16 & 0.03 \\
\hline
\end{tabular}




\section{Stability analysis of surrounding rock mass}

Because of joints, significant geological bedding phenomenon disturbed by excavation may take place. Stratum slips along joint, which would lead to obviously unsymmetrical load.

\subsection{Surrounding rock stress prediction}

To observe stress release and transfer, we need to change the dip angle. The distributions of principal stress with different angles are shown in Fig. 3.

From 3, it can be seen that the joint surface fundamentally changes the stress distribution in rock. This affects not only the direction of principal stress, but also its density. The directions of the maximum and minimum principal stresses are no longer tangential and radial. The physical-mechanical parameters of joint planes are much less than those of rock blocks[16-17]. It is noted that stress is released in the direction parallel to the orientation of the dip angle and distributed uniformly. Rock relaxation is obvious, and even tensile stress appears. Principal stress increases perpendicular to the joint plane, and dis- tributes non-uniformly. The principal stress has a large concentrative degree near the joint plane. The layered stratum around the tunnel is a cantilever beam subjected to bending and shearing. Due to its weak bending resistance, the layered rock mass cannot bear high magnitudes of stress. Bending damage is likely to occur, and structural planes may shear off or open.

For horizontal layered strata, rock blocks are prone to bend in the tension state. When the dip angle is small, the sliding force of the joints can hardly overcome its cohesion. Open zones between joints may form at the left shoulder and the right wall footing. When the dip angle attains a value of $60^{\circ}$, surrounding rock stress at the left shoulder and the right wall footing is larger than that in the symmetric position of the tunnel. For the vertical joint of rock mass, tensile stress perpendicular to the joint would lead to open zones owing to the weak bonding between layered strata. In general, the failure mode in this case is bending-crushing damage at the wall of the tunnel.

\subsection{Displacement prediction}

Controlled convergence is critical to successful construction of an unsymmetrical tunnel in geologically in

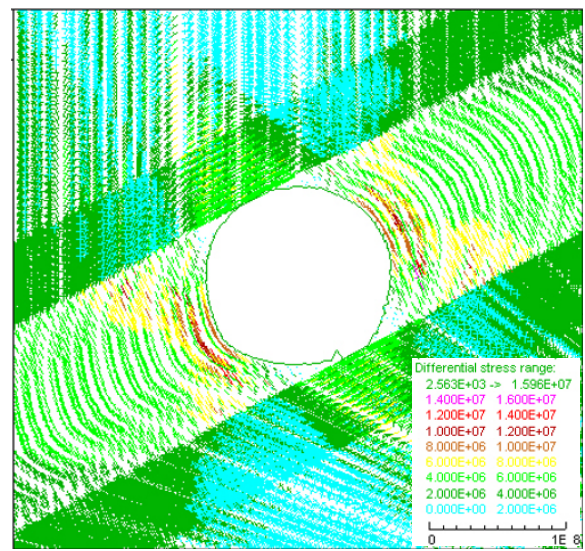

(b) Dipping $30^{\circ}$

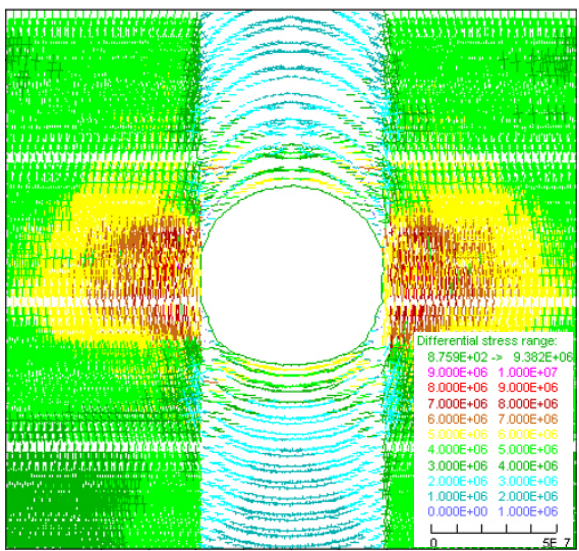

(d) Dipping $90^{\circ}$

(c) Dipping $60^{\circ}$

Fig. 3 Principal stress distribution disturbed by excavation with different dip angles (unit: Pa) 


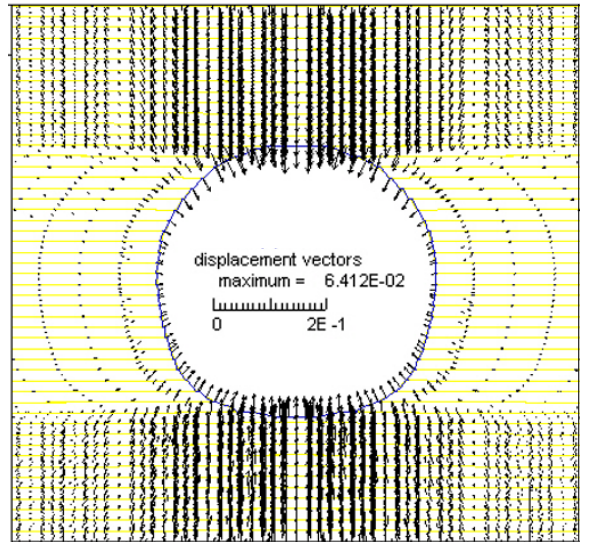

(a) Dipping $0^{\circ}$

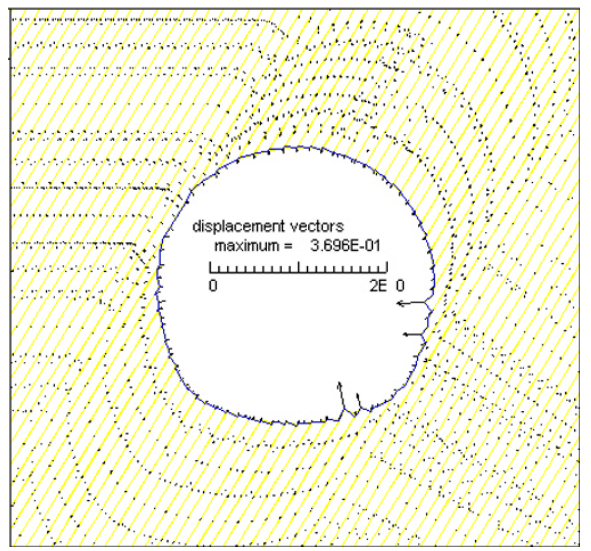

(c) Dipping $60^{\circ}$

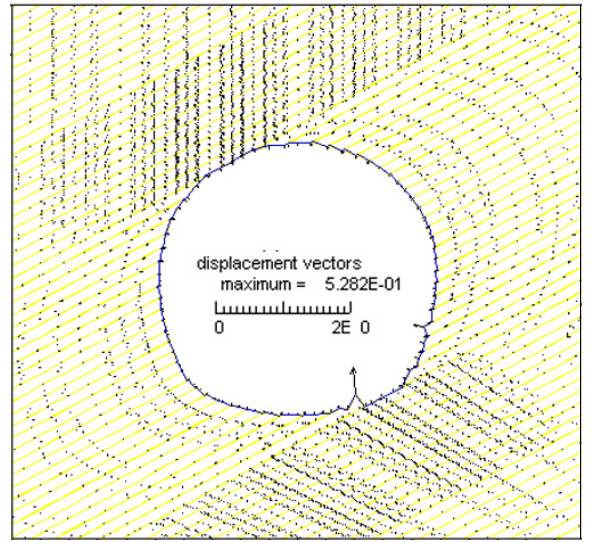

(b) Dipping $30^{\circ}$

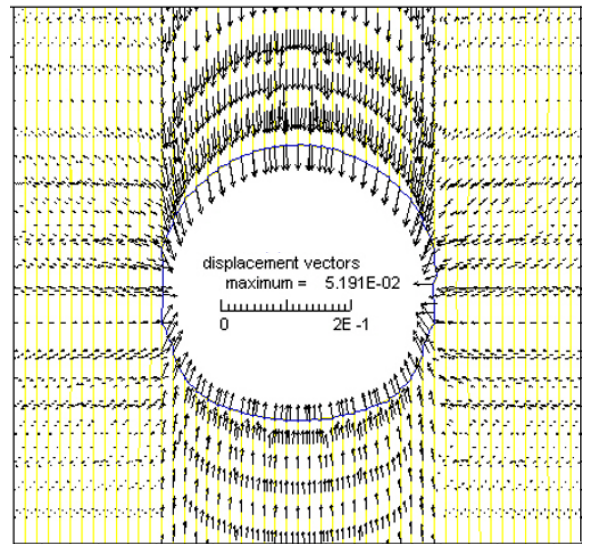

(d) Dipping $90^{\circ}$

Fig. 4 Displacement distributions of surrounding rock with different dip angles (unit: $\mathrm{m}$ )

clined bedding strata. Fig. 4 describes the displacement vector distributions of rock mass under different dip angles, such as $0^{\circ}, 30^{\circ}, 60^{\circ}$, and $90^{\circ}$.

The displacement of rock mass in Fig. 4 is caused by excavation unloading. Because of weak joints, noticeable shear displacement is observed along the structural plane, pointing to the tunnel. The displacement above the wall is larger than that below it. When the joint plane is horizontal, the maximum displacement occurs at the arch and invert, but not at the wall, as shown in Fig. 4(a). Its failure mode is bending damage of the rock block at the arch. When the dip angle is between $30^{\circ}$ and $60^{\circ}$, the maximum displacement occurs at the right shoulder and the left arch footing, which represents an obvious asymmetry as shown in Figs. 4(b) and (c). For the inclined bedding, shear displacement of the rock block is likely to occur along the joint plane. The shear displacement grows sharply, even causing the pitched roof to plump up. Therefore, its failure mode is shear slipping of the joint plane.

When the joint is vertical, the joint cohesion between inclined bedding strata can not resist the downslide strength. The rock mass above the arch glides integrally collapse. Accordingly, reinforcing measures must be adopted to enhance the joint plane cohesion and friction angle, and consequently improve the shear strength of layered strata.

\subsection{Open zone prediction}

Weak cohesion between layered strata cannot resist significant amounts of tensile stress induced by excavation. Fig. 5 shows the distributions of open zone under different dip angles.

Open zone, where tangential and normal stress is zero, is characterized by potential instability for tunnels. From Fig. 5, open zone takes place perpendicular to the joint plane, and parallel with the maximum principal stress direction. The area of an open zone increases at first, and then decreases with dip angle increasing. When the dip angle is small, the principal stress of joints can hardly overcome its cohesion, and joints are prone to open up. Stress intensity is adjusted by the open zone, which makes the adjacent rock strength decrease. When the dip angle is between $30^{\circ}$ and $45^{\circ}$, open zones would appear at shoulders mainly. When the dip angle is between $45^{\circ}$ and $75^{\circ}$, joints have a great influence on the stability of the surrounding 
rock. Furthermore, the corresponding angle for the maximum open area is among $60^{\circ}$ and $75^{\circ}$. Therefore, the failure mode for inclined bedding is shear slipping of joint planes. Bolts should be installed perpendicular to the joints to improve the shearing stiffness [18-19].

\section{Mechanical response of bolts in jointed rock mass}

According to the general purpose graph of tunnel for $250 \mathrm{~km} / \mathrm{h}$ of passenger dedicated lines [9-10], the spacing of bolts in the circumferential direction is $1.2 \mathrm{~m}$. For different dip angles, the maximum axial forces of bolts

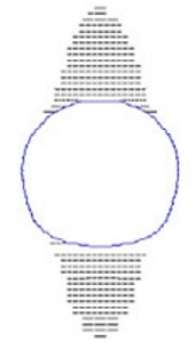

(a) Dipping $0^{\circ}$

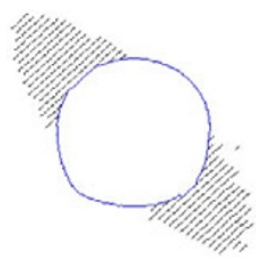

(c) Dipping $45^{\circ}$

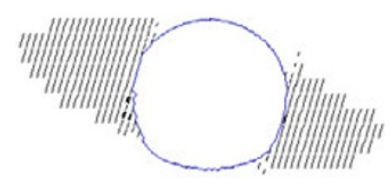

(e) Dipping $75^{\circ}$

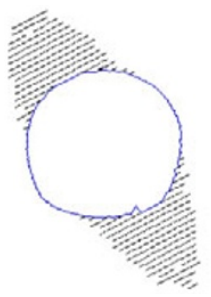

(b) Dipping $30^{\circ}$

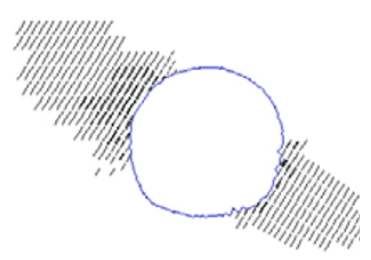

(d) Dipping $60^{\circ}$

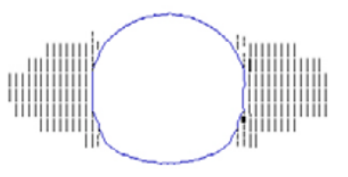

(f) Dipping $90^{\circ}$
Fig. 5 Open zone disturbed by excavation with different dip angles in symmetrical positions of tunnel and the angle between bolt and joint plane are summarized in Table 3 . Here, $\beta$ is the angle between bolt and joint plane, and $F$ is the maximum axial force. The relationship between them can be reflected intuitively by the distribution curves in Fig. 6.

From Table 3, when the dip angle is small, the axial force difference in symmetrical positions at both sides is almost the same, indicating that the inclined bedding is not prone to shear slip [20]. The failure mode is consistent with the sheet crack theory. As the dip angle increases, a high-density unsymmetrical load is formed. The axial force difference between both sides enlarges. Similarly, the load on the left side is more than that at the right side. Furthermore, the trend of stratum sliding along the weak structure plane is amplified. Due to the bolt axial tension, layered strata show an integral bending deformation under bending moment and an improved flexural

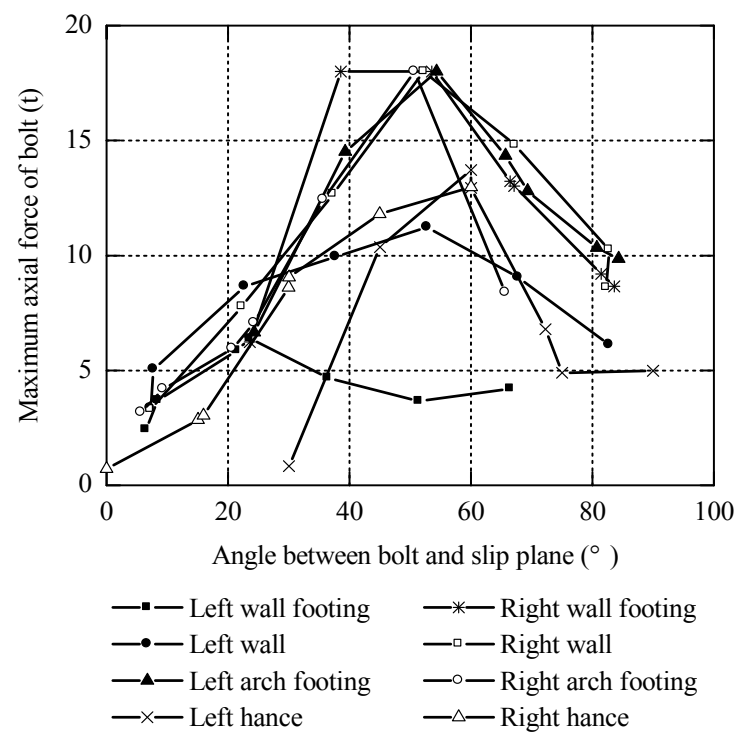

Fig. 6 Relationship of the bolts maximum axial force with the angle between bolt and slip plane

Table 3 The maximum axial force of bolts

\begin{tabular}{|c|c|c|c|c|c|c|c|c|c|c|}
\hline \multirow{2}{*}{ Position } & \multicolumn{2}{|c|}{$0^{\circ}$} & \multicolumn{2}{|c|}{$30^{\circ}$} & \multicolumn{2}{|c|}{$60^{\circ}$} & \multicolumn{2}{|c|}{$75^{\circ}$} & \multicolumn{2}{|c|}{$90^{\circ}$} \\
\hline & $\beta\left(^{\circ}\right)$ & $F(\mathrm{t})$ & $\beta\left(^{\circ}\right)$ & $F(\mathrm{t})$ & $\beta\left(^{\circ}\right)$ & $F(\mathrm{t})$ & $\beta\left(^{\circ}\right)$ & $F(\mathrm{t})$ & $\beta\left(^{\circ}\right)$ & $F(\mathrm{t})$ \\
\hline Left wall footing & 23.57 & 6.39 & 6.43 & 2.42 & 36.43 & 4.67 & 51.43 & 3.66 & 66.43 & 4.20 \\
\hline Right wall footing & 23.57 & 6.23 & 53.57 & 18.00 & 83.57 & 8.66 & 81.43 & 9.19 & 66.43 & 13.23 \\
\hline Left wall & 7.26 & 3.36 & 22.74 & 8.65 & 52.74 & 11.22 & 67.74 & 9.05 & 82.74 & 6.11 \\
\hline Right wall & 7.26 & 3.30 & 37.26 & 12.67 & 67.26 & 14.80 & 82.26 & 8.61 & 82.74 & 10.25 \\
\hline Left arch footing & 24.30 & 6.65 & 54.30 & 18.00 & 84.30 & 9.85 & 80.70 & 10.33 & 65.70 & 14.35 \\
\hline Right arch footing & 24.30 & 7.07 & 5.70 & 3.16 & 35.70 & 12.43 & 50.70 & 18.00 & 65.70 & 8.39 \\
\hline Left hance & 59.98 & 13.72 & 89.98 & 4.99 & 60.02 & 12.14 & 45.02 & 10.37 & 30.02 & 0.82 \\
\hline Right hance & 59.98 & 12.97 & 29.98 & 9.04 & 0.02 & 0.71 & 15.02 & 2.84 & 30.02 & 6.01 \\
\hline
\end{tabular}


rigidity and strength. From Fig. 6, the bolt axial force on the right side is greater than that on the left side generally. From the view of the angle between the bolt and joint plane, when the angle is more than $23^{\circ}$, the bolt can significantly enhance the shear stiffness of joints, and restrain the shear slip between layered strata.

\section{Surrounding rock pressure for geological bedding unsymmetrical tunnel}

\subsection{Surrounding rock pressure on support}

The surrounding rock pressure on support under different dip angles of inclined bedding is shown in Table 4 and Fig. 7.

Table 4 Surrounding rock pressure on support $\mathrm{kPa}$

\begin{tabular}{cccccc}
\hline Dip angle $\left({ }^{\circ}\right)$ & $A$ & $B$ & $C$ & $D$ & $E$ \\
\hline 30 & 1.25 & 1.13 & 0.97 & 0.76 & 0.73 \\
45 & 1.56 & 1.32 & 1.06 & 0.84 & 0.81 \\
60 & 1.65 & 1.57 & 1.30 & 1.08 & 1.16 \\
75 & 1.61 & 1.65 & 1.64 & 1.28 & 1.32 \\
\hline
\end{tabular}

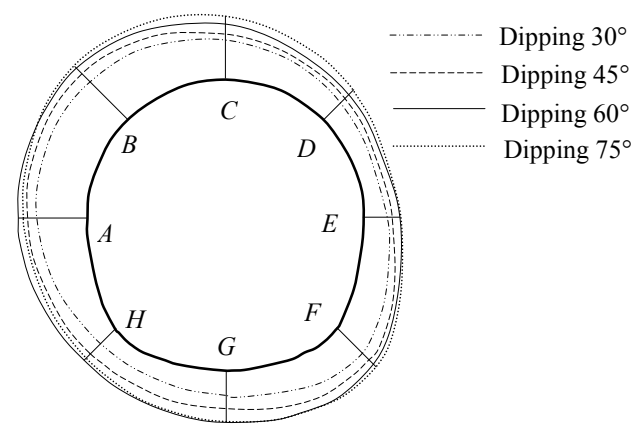

Fig. 7 Surrounding rock pressure distribution with different dip angles

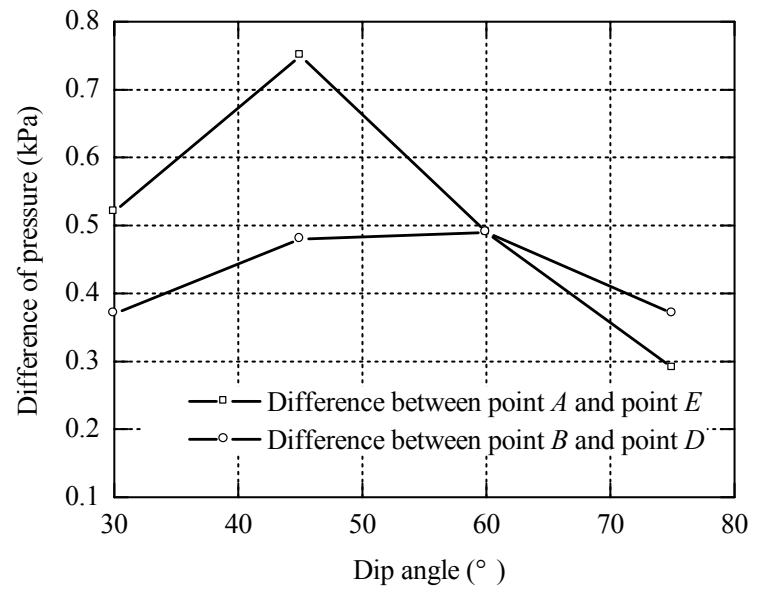

Fig. 8 Relationship between surrounding rock pressure difference and dip angles
From Table 4 and Fig. 7, the values of surrounding rock pressure on support at point $D$ and point $E$ are smaller than those at symmetric positions $B$ and $A$. That is, the surrounding rock pressure on the left wall and shoulder is more than that on the right. The relationship between the surrounding rock pressure difference and dip angle is shown in Fig. 8.

From Fig. 8, the relationship between surrounding rock pressure difference and dip angle is not linear. When the dip angle is in the range of $30-45^{\circ}$, the difference of surrounding rock pressures on both sides increases as the dip angle increases. On the other hand, when the dip angle of the inclined bedding increases in the range of $45-75^{\circ}$, the surrounding rock pressures on the left and right sides tend to a symmetric state, and the surrounding rock pressure at the arch increases, but at a slower rate. As the dip angle of the inclined bedding increases within $60^{\circ}$, the unsymmetrical load on support increases, and the surrounding rock pressure on both sides increases by a small magnitude. Therefore, the lining of left wall, arch, and shoulder is prone to damage, which is consistent with spot observations as presented in Fig. 1.

\subsection{Asymmetric design of support}

According to the above-stated results, an asymmetric lining structure can be adopted to reinforce the geologically inclined bedding asymmetric load tunnel in design phase, by increasing the thickness, reinforcement ratio, and concrete grade of the left wall, or employing polypropylene fiber shotcrete for the support. It could improve the safety and strength of the lining structure.

\section{Conclusions}

(1) In terms of layered strata, excavation can induce rock mass slips or fractures along the joint plane, and the unsymmetrical load is closely related to the dip angle of layered stratum. Open zones occur in places perpendicular to the orientation of the joint plane, and parallel to the maximum principal stress direction. When the joint is vertical, it will lead to shear failures.

(2) When strata are horizontal, or dip angle is small, open zone appears at the arch and invert and induces stratum disjunction easily. With the dip angle increasing, tunnel excavating can cause joint shear zones, and lead to obvious geological bedding unsymmetrical load. Furthermore, the shear trend is augmented along the joint. When the joint dip angle is in the range of $75-90^{\circ}$, the failure mode is flexural crushing. The restraining effect of two sides weakens with almost vertical dips. Furthermore, shear failure instability trend will take place and the tunnel collapses evenly. 
(3) Bolts play a paramount role in enhancing the shear stiffness of joints, restraining the shear slip between layered strata, and improving the surrounding rock stability. When the angle between bolt and joint plane is larger than $23^{\circ}$, bolts can have an obvious anchoring role. Unfortunately, in the general purpose graph of tunnel for $250 \mathrm{~km} / \mathrm{h}$ of passenger dedicated lines [9-10], the bolts are of equal length and even spacing. The rationale behind this is worthy of further study.

(4) For geologically inclined bedding, the surrounding rock pressure at the left wall is more than that at the right wall. In addition, lining may be damaged at the left shoulder and wall. When the dip angle is in the range of $30-45^{\circ}$, the difference of surrounding rock pressure on both sides increases sharply. When the dip angle is in the range of $45-75^{\circ}$, the rate of increase is slower. However, the surrounding rock pressure on the left and right side tends to be symmetric when the dip angle is larger than $75^{\circ}$.

(5) In accordance with the surrounding rock pressure distribution of geologically inclined bedding, the reinforcing measures of lining should be adopted, such as increasing thickness of left wall, reinforcement ratio, and strength of concrete. In addition, extra-long bolts can be used to prevent or reduce the unsymmetrical load on lining induced by the shearing slip during excavation. These measures can guarantee the safety and durability of lining during tunnel construction.

\section{Acknowledgements}

The work was supported by the National Natural Science Foundation of China (No. 51078318).

\section{References}

[1] S.G. Chen, H. Zhang, X.R. Tan, et al., Key technologies for construction of Jinping traffic tunnel with an extremely deep overburden and a high water pressure, Journal of Modern Transportation, 2011, 19(2): 94-103.

[2] B. Shen, N. Barton, The disturbed zone around tunnels in jointed rock masses, International Journal of Rock Mechanics and Mining Sciences, 1997, 34(1): 117-125.

[3] J. Idris, M. Al-Heib, T. Verdel, Numerical modelling of masonry joints degradation in built tunnels, Tunnelling and Underground Space Technology, 2009, 24(6): 617626.

[4] H.S. Ma, H.G. Ji, Experimental study of the effect of joint orientation on fragmentation modes and penetration rate under TBM disc cutters, Chinese Journal of Rock Mechanics and Engineering, 2011, 30(1): 155-163 (in Chinese).

[5] G.J. Wang, Mechanical state of jointed rock mass and support structure of large tunnel during construction process, Chinese Journal of Rock Mechanics and Engineering, 2005, 24(8): 1328-1334 (in Chinese).
[6] G. Liu, J. Zhao, H.W. Song, et al., Physical modelling of effect of joint density on deformation and failure of surrounding rocks, Chinese Journal of Geotechnical Engineering, 2007, 29(11): 1737-1741 (in Chinese).

[7] N. Halakatevakis, A.I. Sofianos, Strength of a blocky rock mass based on an extended plane of weakness theory, International Journal of Rock Mechanics and Mining Sciences, 2010, 47(4): 568-582.

[8] T. Solak, Ground behavior evaluation for tunnels in blocky rock masses, Tunnelling and Underground Space Technology, 2009, 24(3): 323-330.

[9] The Professional Standards Compilation Group of People's Republic of China, TB1003-2005 code for design of railway tunnel, Beijing: China Railway Publishing House, 2005 (in Chinese).

[10] B.S. Guan, Y. Zhao, Construction Technique of Tunnels with Soft Surrounding Rocks, Beijing: China Communications Press, 2011 (in Chinese).

[11] Q.M. Gong, Y.Y. Jiao, J. Zhao, Numerical modeling of the effects of joint spacing on rock fragmentation by TBM cutters, Tunnelling and Underground Spacing Technology, 2006, 21(1): 46-55.

[12] S.R. Yi, L.T. Nie, Y.H. Chen, et al., Reasonable compensation coefficient of maximum gradient in long railway tunnels, Journal of Modern Transportation, 2011, 19(1): 12-18.

[13] K. Feng, C. He, Z.X. Su, Prototype test on failure characteristics of segmental lining structure for Nanjing Yangtze river tunnel, Journal of Southwest Jiaotong University, 2011, 46(4): 564-571 (in Chinese).

[14] Z. Wang, G.H. Li, Z.J. Zhang, et al., Effect of fire fighting water on compressive strength of concrete in tunnel fire, Journal of Southwest Jiaotong University, 2011, 46(2): 223-227, 240 (in Chinese).

[15] J. S. Moon, Representativeness of jointed rock mass hydraulic conductivity obtained from packer tests for tunnel inflow rate estimate, International Journal of Rock Mechanics and Mining Sciences, 2011, 48(5): 836-844.

[16] N. Bahrani, D. D. Tannant, Field-scale assessment of effective dilation angle and peak shear displacement for a footwall slab failure surface, International Journal of Rock Mechanics and Mining Sciences, 2011, 48(4): 565-579.

[17] T.E. Noble, J.M. Dixon, Structural evolution of foldthrust structures in analog models deformed in a large geotechnical centrifuge, Journal of Structural Geology, 2011, 33(2): 62-77.

[18] L.R. Alejano, A.M. Ferrero, P. Ramírez-Oyanguren, et al., Comparison of limit-equilibrium, numerical and physical models of wall slope stability, International Journal of Rock Mechanics and Mining Sciences, 2011, 48(1): 16-26.

[19] J.F. Noël, G. Archambault, Numerical simulation of kink zone instability in fractured rock masses, International Journal of Rock Mechanics and Mining Sciences, 2009, 46(6): 1001-1009.

[20] F. Nenna, A. Aydin, The role of pressure solution seam and joint assemblages in the formation of strike-slip and thrust faults in a compressive tectonic setting; The Variscan of south-western Ireland, Journal of Structural Geology, 2011, 33(11): 1595-1610. 